Research Article

\title{
Multiresponse Parameter Optimization for the Composite Tape Winding Process Based on GRA and RSM
}

\author{
Qi Hong (iD) and Yaoyao Shi \\ School of Mechanical Engineering, Northwestern Polytechnical University, Shaanxi 710072, China \\ Correspondence should be addressed to Qi Hong; 407460979@qq.com
}

Received 23 March 2020; Revised 1 June 2020; Accepted 16 June 2020; Published 15 July 2020

Academic Editor: Marek Lefik

Copyright (c) 2020 Qi Hong and Yaoyao Shi. This is an open access article distributed under the Creative Commons Attribution License, which permits unrestricted use, distribution, and reproduction in any medium, provided the original work is properly cited.

\begin{abstract}
Composite tape winding is an important forming process of composite materials, which can ensure good performance of composite products. Selection and control of key process parameters in the winding process have a great influence on the properties of products, such as void content and residual stress of products. Through experimental analysis, the residual stress and void content of the composite products are not the minimum when the prepreg winding process is carried out by using the empirical process parameters. To solve this multiobjective optimization problem, experiments were conducted using the Box-Behnken design. The multiobjective optimization problem is converted to a single-objective problem using grey relational analysis (GRA). Principal component analysis (PCA) is used to quantify the relative contributions of residual stress and void content. Regression analysis of grey relational grade (GRG) based on the experimental data was used to develop a second-order GRG prediction model. The winding process parameters were optimized with response surface methodology (RSM), and the winding experiments were carried out with these parameters. The experimental results show that the best combination of process parameters yields the best GRG results with better void content and residual stress.
\end{abstract}

\section{Introduction}

Due to good mechanical, chemical, and physical properties, composite materials are increasingly used. Advanced resin matrix composites have been widely used in the manufacture of solid rocket motor nozzles, parts of ablation and thermal protection materials, launch tubes, and special equipment for the spacecraft. They have many advantages including low density, high strength and stiffness ratios, good corrosion resistance, and ease of integral molding [1-3]. The properties of composite prepreg tape winding products depend on the properties of the materials themselves, molding process parameters, and control accuracy. Therefore, controlling the winding process and the process parameters is the key to ensuring the products have the desired properties. The main parameters in the composite prepreg tape winding process include winding temperature, tension, force, and winding speed [4-8]. An adaptive genetic algorithm with minimum product weight is proposed in $[9,10]$, and RSM (RSM is a statistical method to solve multivariable problems, multiple quadratic regression equations which are used to fit the functional relationship between factors and response values, and through the analysis of regression equations to find the optimal process parameters) is used to predict the strength reliability of the composite material in high-pressure hydrogen storage vessels. One study analyzed the coupling mechanism in composite material winding process parameters and presented a quadratic regression model for the interlaminar shear strength based on RSM, yielding the optimal combination of process parameters [11]. In [12], a hybrid neural network is used to determine the optimal curing time, which can ensure complete curing of composite products.

One can see from the literature that prior research mainly focused on single-objective optimization, but the filament winding products have multiple objectives to be evaluated. GRA is a method of multivariate statistical analysis. In general, we want to understand the strength of a 
project affected by other factors in a grey system. In [13-16], GRA is introduced to solve complex relations between multiple factors and variables. GRA has been successfully applied in many engineering fields, such as welding [17, 18], high-speed machining [19-22], mechanical design of positioning platforms $[23,24]$, and wire electrical discharge machining [25-30].

The primary work in this paper includes calculating grey correlation coefficients (GCCs) between residual stress and porosity based on experimental data. GRG can be subsequently obtained using a weighting method. A second-order prediction model for GRG is established based on experimental data with the use of RSM. The influence of process parameters on GRG is analyzed, and the optimum combination of process parameters is obtained and verified through experiments. The results in this paper show that a particular multiobjective problem can be transformed into a single-objective problem using GRA. The optimum combination of process parameters in the composite prepreg tape winding process can be subsequently determined, and the residual stress and void content of composite products can be controlled.

\section{Experiment Procedure and Results}

2.1. Composite Prepreg Tape Winding Process. In the process of composite tape winding, tension is a key process parameter. Tension is applied with a magnetic powder brake during the winding process. Tension can straighten the prepreg winding so that the fiber can bear the load evenly. The applied tension can remove air bubbles, make the winding products more compact, and facilitate resin penetration. In the winding process, the core mold rotates at a constant speed, and the resin is heated to the melting state by the hot pressure roller and the hot blower. As shown in Figure 1, heat comes from the internal heating wire in the hot pressure roller, which helps reduce the resin speed and increase the degree of contact between the layers. In the melting zone, the hot pressure roller exerts positive force on the tape layer, causing the prepreg tape and the tape layer to come into close contact. On the contrary, it helps reduce void content by reducing bubbles between interlayer contacts.

The winding of the prepreg tape is essentially a process of continuous fusion between the prepreg tape and the base layer. When a certain winding pressure and temperature are applied to the winding layer and prepreg, the surface geometry will be deformed, as shown in Figure 2. The selfbonding process begins when the winding layer is in close contact with the prepreg surface. After a period of time, the polymer chain penetrates completely and entangles with the adjacent interface so that the matrix on the interface forms the bulk polymer again, and the two surfaces are fully integrated.

2.2. Experimental Procedures. A KUKA robot (XGD-1200) (KUKA, Augsburg, Germany) is the primary piece of equipment used in our experiments, as shown in Figure 3. In order to ensure the control accuracy of the winding process, a high-precision deviation correction control system and layered superposition winding are used in the experiment. Circumferential winding experiment is carried out with the orthogonal prepreg tape. T300/epoxy orthogonal prepreg tape is purchased from Daobo Composites Co., Ltd., Xi'an, China. The winding mandrel is a 45 steel cylinder which is $150 \mathrm{~mm}$ in external diameter and $1200 \mathrm{~mm}$ in length. The parameters of the prepreg tape are fiber volume fraction, tape width, and tape thickness, which are $56 \pm 2 \%, 80 \mathrm{~mm}$, and $0.25 \mathrm{~mm}$, respectively. In this experiment, the ambient temperature is $20 \pm 2^{\circ} \mathrm{C}$, and the relative humidity is $25 \pm 2 \%$. The curing process has a great influence on the properties of the products. During the curing process, the heating rate is kept at $2.5^{\circ} \mathrm{C} / \mathrm{min}$. When the curing temperature reaches $150^{\circ} \mathrm{C}$, it is needed to keep heating for 150 minutes, and the curing pressure is $0.15 \mathrm{MPa}$.

\subsection{Sample Preparation and Measurement Method}

2.3.1. Residual Stress. In the process of composite prepreg winding, due to the deformation of the product, the residual stress is inevitable. Residual stress is a key index to evaluate the properties of composite products, which is selected as one of the optimization objectives. When examining residual stress in composite annular parts, a slot is cut along the radial direction, and the slot position will change due to the residual stress moment. Figure 4 shows the change in slot displacement after closure of the compound ring, which can be measured with an electron microscope. The circumferential residual stress in the composite ring can be calculated with the following equations [31, 32]:

$$
\begin{gathered}
\sigma_{\theta}=-\frac{4 M_{r}}{k}\left(\frac{-R_{a}^{2} R_{b}^{2}}{r^{2}} \ln \frac{R_{b}}{R_{a}}+R_{b}^{2} \ln \frac{r}{R_{b}}+a^{2} \ln \frac{R_{a}}{r}+R_{b}^{2}-R_{a}^{2}\right) \\
\left\{\begin{array}{l}
M_{r}=-\frac{\Delta E}{8 \pi}\left(\frac{\left(R_{b}^{2}-R_{a}^{2}\right)^{2}-4 R_{a}^{2} R_{b}^{2}\left[\ln \left(R_{b} / R_{a}\right)\right]^{2}}{2\left(R_{b}^{2}-R_{a}^{2}\right)}\right) \\
k=\left(R_{b}^{2}-R_{a}^{2}\right)^{2}-4 R_{a}^{2} R_{b}^{2}\left[\ln \left(R_{b} / R_{a}\right)\right]^{2} \\
\Delta=\Delta_{1}+\Delta_{2}
\end{array}\right.
\end{gathered}
$$

where $r$ is the current position, $\Delta$ is the total displacement of the slot, $M_{r}$ is the bending moment per unit width, $E$ is the circumferential elastic modulus, and $R_{a}$ and $R_{b}$ are the inner and outer radii, respectively.

The magnitude of the residual stress is the average value of the composite outer and inner rings, which can be defined as follows:

$$
\sigma_{\Delta}=\frac{\left|\sigma_{\theta}\left(r=R_{a}\right)\right|+\left|\sigma_{\theta}\left(r=R_{b}\right)\right|}{2} .
$$

2.3.2. Void Content. Voids in composite tape winding products are defects that principally exist between tape layers due to residual air bubbles, resin flow, and sufficient 


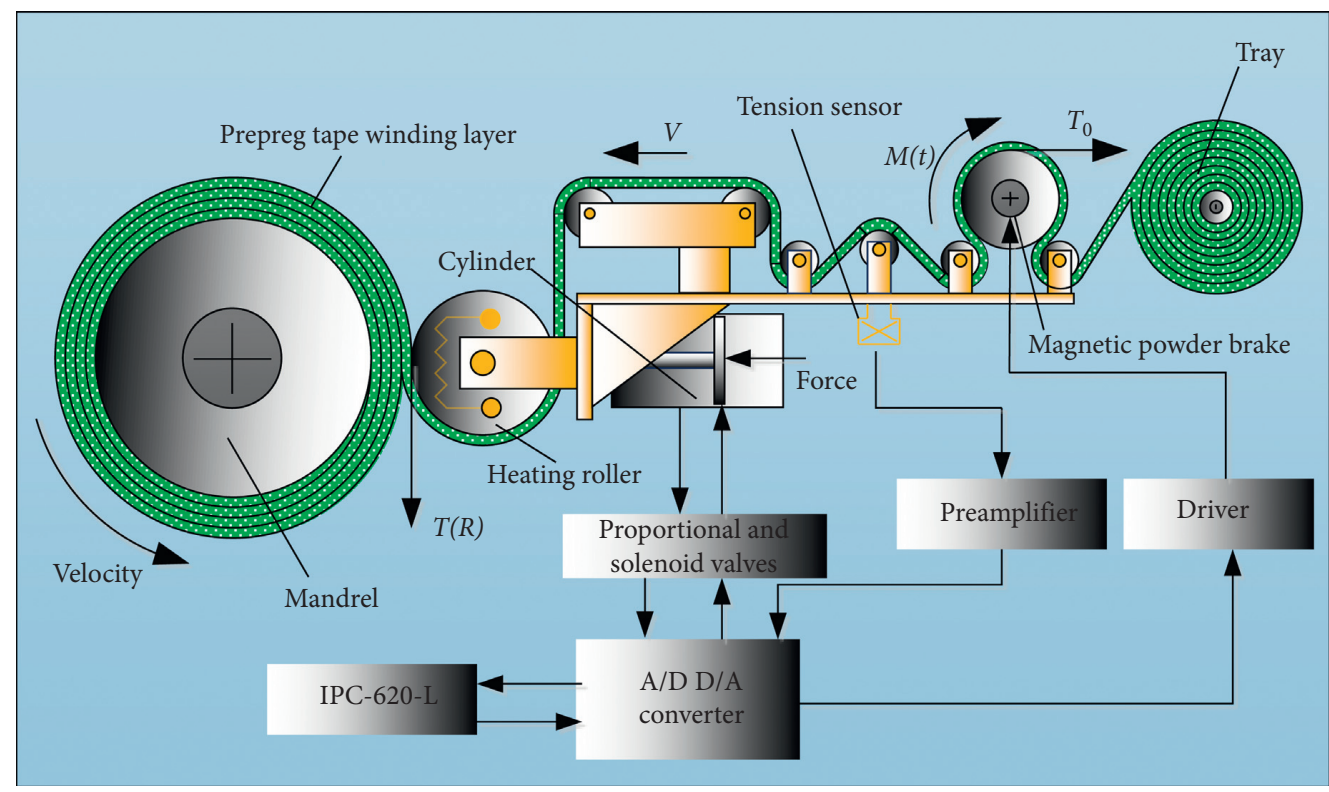

Figure 1: Process schematic of composite tape winding.

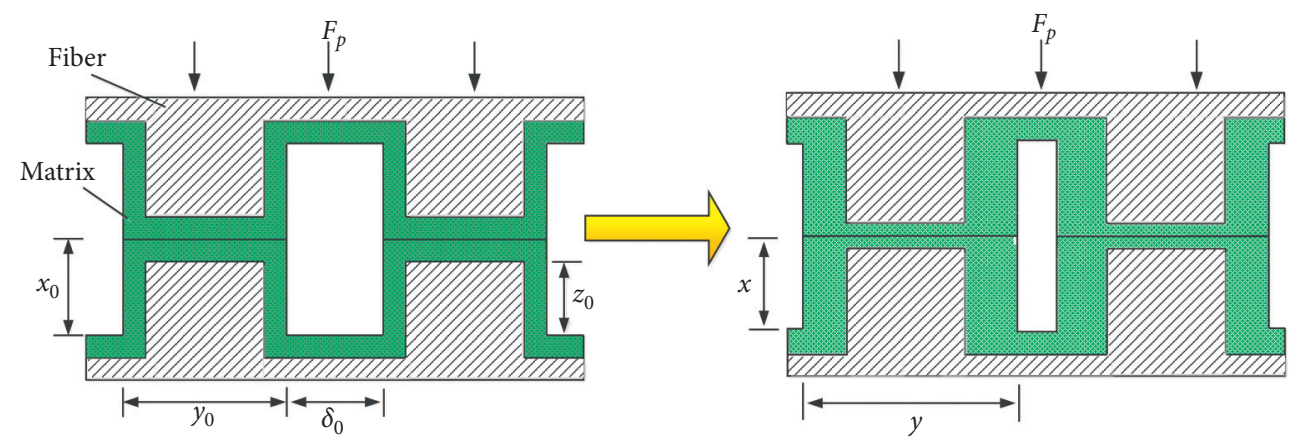

FIGURE 2: Schematic of microcosmic deformation on the composite prepreg tape surface.

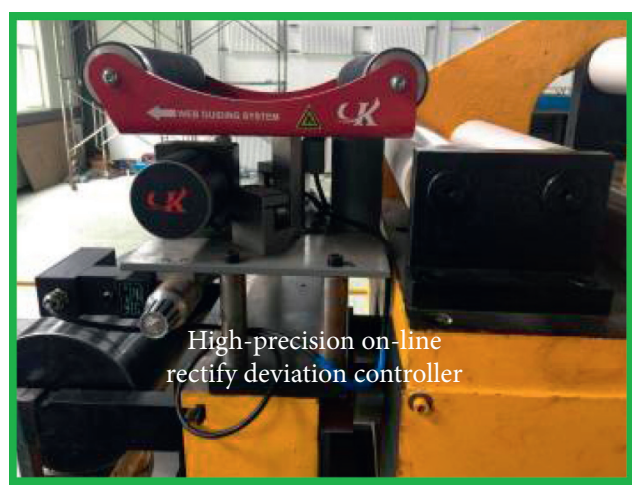

(a)

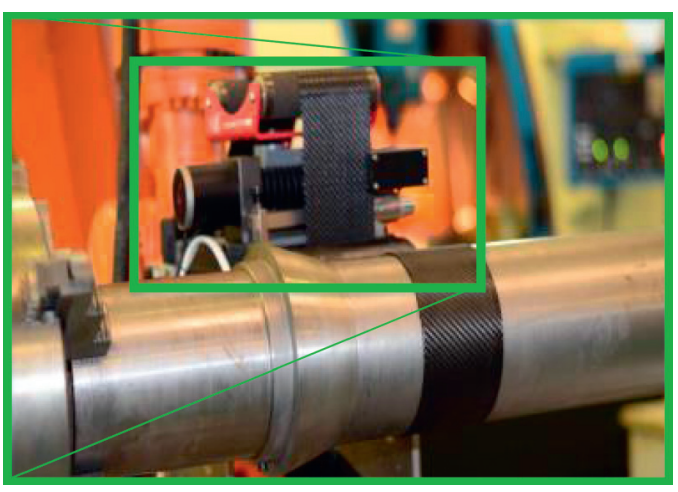

(b)

FIgURE 3: Composite tape winding robot (XGD-1200).

compaction during resin flow. Density measurements, microscopy [33-39], ultrasonic attenuation [40], and X-ray computed tomography [41] can be used to measure void content. The electronic micrograph method has the highest porosity detection accuracy, which is specified by GB/ T3365-2008 [42]. The specimen is sampled and observed at the marked position, as shown in Figure 5. The samples are cut on the composite ring product, with a length, width, and height of $20 \mathrm{~mm}, 10 \mathrm{~mm}$, and $10 \mathrm{~mm}$, respectively. The samples are ground and polished under flowing water, then the polished specimen is observed under a microscope, and the process of measuring void content is shown in Figure 6. 


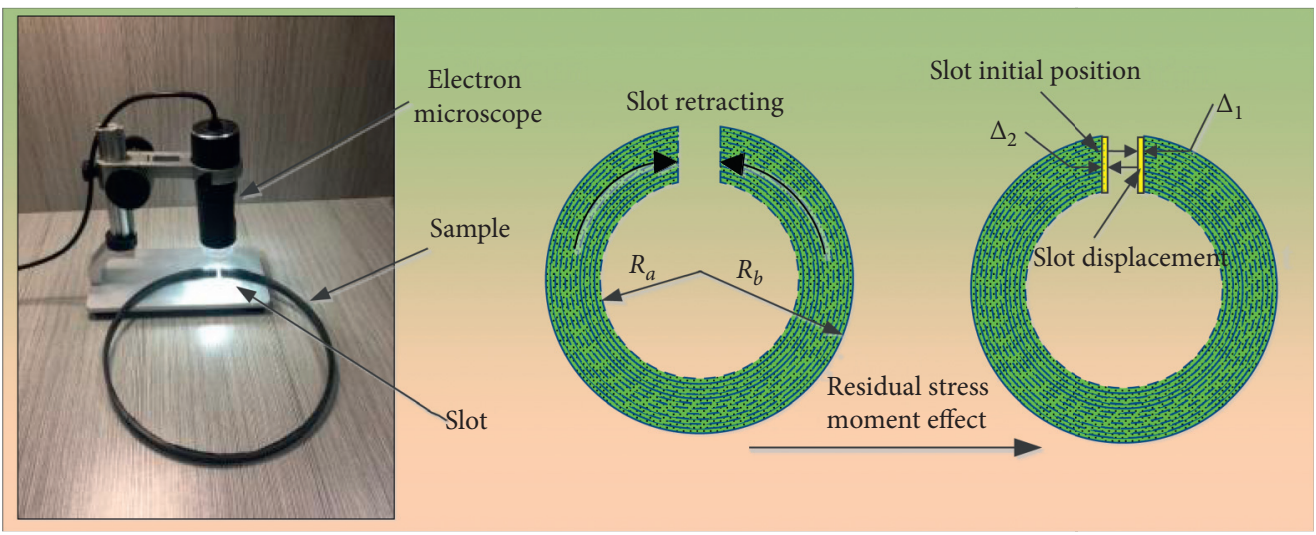

Figure 4: Residual stress measurement method.

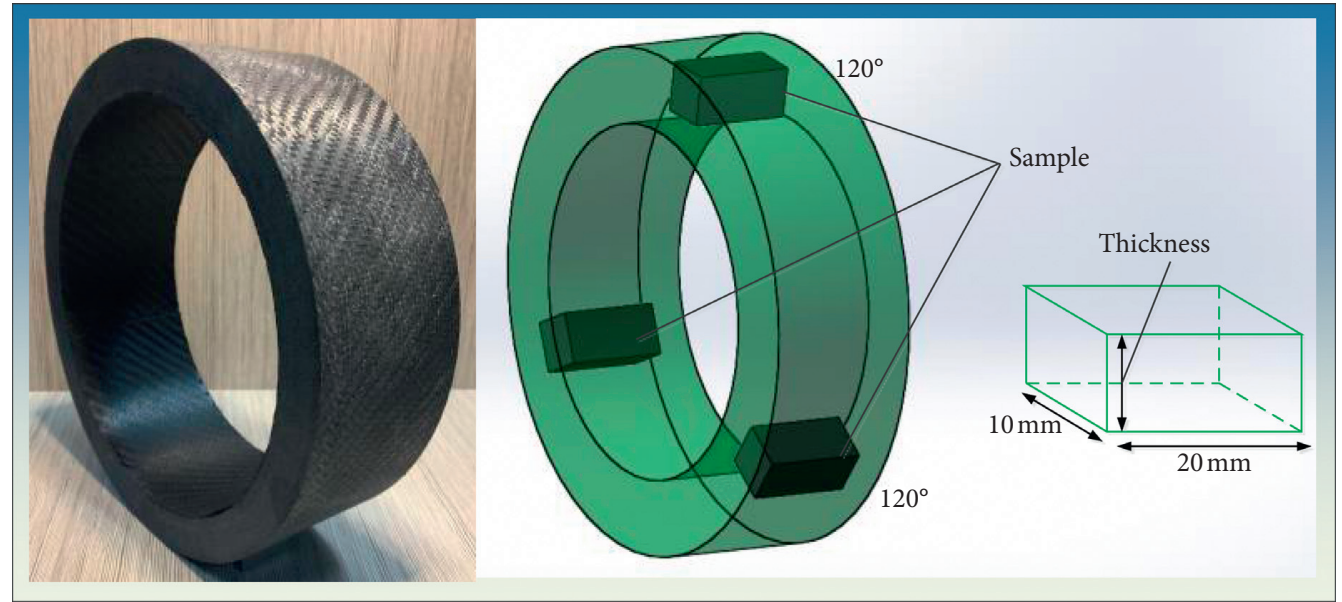

FIGURE 5: Sketch of cutting the testing sample.

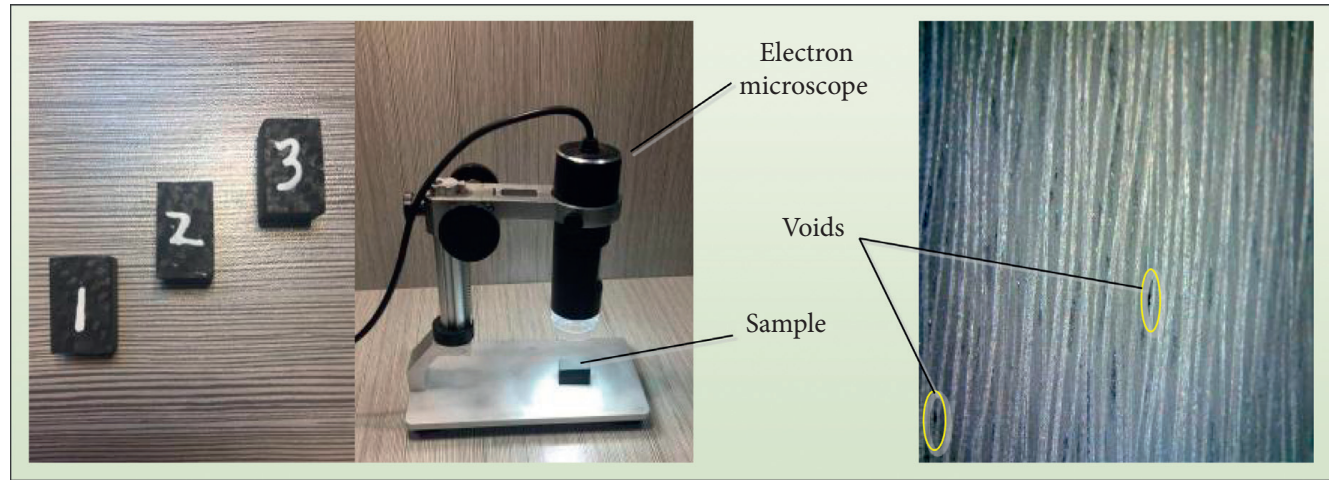

FIgURE 6: Void content measurement process of composite products.

The calculation formula of void content is shown in the following equation:

$$
X=\frac{S_{\mathrm{v}}}{A} \times 100 \%,
$$

where $X$ is the void content, $A$ is the cross-sectional area, and $S_{\mathrm{v}}$ is the total void area of the sample.
2.4. Experiment Results. Temperature, winding speed, roller force, and winding tension are taken as the independent experimental variables, and residual stress and porosity are the response variables and design variable values according to actual working conditions. The four-factor and three-level BBD experiment design method was used to reduce costs. $\mathrm{BBD}$ is a response surface design type, which does not 
include embedding factor or partial factor design. BBD usually has fewer design points, and each factor always has 3 levels. According to the actual production experience, the temperature setting range is $50-100^{\circ} \mathrm{C}$. When the prepreg tape temperature is lower than $50^{\circ} \mathrm{C}$, the resin matrix is difficult to reach the melting state, and when the temperature is too high, it will easily lead to early curing of the resin. The pressure setting range is $1000-2000 \mathrm{~N}$; when the pressure is less than $1000 \mathrm{~N}$, the contact between the laminate and prepreg tape is not enough, and when the pressure is too large, the winding products will be deformed. The setting range of tension is $100-500 \mathrm{~N}$; too small tension will increase the number of air bubbles between layers, and too large tension will lead to the fracture of the prepreg tape. The speed setting range is $5-15 \mathrm{rpm}$, and too fast winding speed is not conducive to machining. The designed level of process parameters is shown in Table 1, and the experimental results are shown in Table 2 .

\section{Grey Relational Grade Calculation from Experimental Data}

\subsection{GRG Calculation Process}

Step 1: experimental void content and residual stress data were collected and used to carry out a standardized treatment. Composite tape winding products with lower void content and residual stress are desirable. Therefore, the experimental data can be expressed as follows:

$$
x_{i}^{*}(k)=\frac{\max x_{i}^{o}(k)-x_{i}^{o}(k)}{\max x_{i}^{o}(k)-\min x_{i}^{o}(k)},
$$

where $x_{i}^{o}(k)$ is the original sequence, $x_{i}^{*}(k)$ is the comparison sequence, $k=1,2, \ldots, n, i=1,2, \ldots, m$, and $n$ and $m$ are the total number of response variables and experimental runs.

Step 2: the grey correlation coefficient can be calculated by the following equation:

$$
\left\{\begin{array}{l}
\gamma\left(x_{0}^{*}(k), x_{i}^{*}(k)\right)=\frac{\Delta_{\min }+\zeta \Delta_{\max }}{\Delta_{0 i}(k)+\zeta \Delta_{\max }} \\
\Delta_{0 i}(k)=\left|x_{0}^{*}(k)-x_{i}^{*}(k)\right| \\
\Delta_{\max }=\max _{i} \max _{j} \Delta_{0 i}(k) \\
\Delta_{\min }=\min _{i} \min _{j} \Delta_{0 i}(k)
\end{array}\right.
$$

where $\Delta_{0 i}(k)$ is the deviation sequence, $x_{0}^{*}(k)$ is the reference sequence, and $\zeta \in[0,1]$ is the distinguishing coefficient.

Step 3: calculation of the weight value for response variables: in this paper, the contributions of void
TABLE 1: Level of process parameters.

\begin{tabular}{lccccc}
\hline \multirow{2}{*}{$\begin{array}{l}\text { Experimental } \\
\text { parameters }\end{array}$} & Symbol & Unit & \multicolumn{4}{c}{$\begin{array}{c}\text { Level of experimental } \\
\text { parameters }\end{array}$} \\
& & & Level 1 & Level 2 & Level 3 \\
\hline Temperature & $A$ & ${ }^{\circ} \mathrm{C}$ & 50 & 75 & 100 \\
Tension & $B$ & $\mathrm{~N}$ & 100 & 300 & 500 \\
Force & $\mathrm{C}$ & $\mathrm{N}$ & 1000 & 1500 & 2000 \\
Velocity & $\mathrm{D}$ & $\mathrm{rpm}$ & 5 & 10 & 15 \\
\hline
\end{tabular}

\begin{tabular}{|c|c|c|c|c|c|c|}
\hline \multirow[b]{2}{*}{ No. } & \multicolumn{4}{|c|}{ Process parameters } & \multicolumn{2}{|c|}{ Objective value } \\
\hline & $A$ & $B$ & $C$ & $D$ & $\begin{array}{l}\text { Residual stress } \\
(\mathrm{MPa})\end{array}$ & $\begin{array}{c}\text { Void content } \\
(\%)\end{array}$ \\
\hline 1 & 100 & 100 & 1500 & 10 & 12.12 & 0.97 \\
\hline 2 & 75 & 500 & 1500 & 15 & 20.05 & 1.56 \\
\hline 3 & 75 & 300 & 1500 & 10 & 13.26 & 0.33 \\
\hline 4 & 75 & 300 & 1500 & 10 & 13.53 & 0.44 \\
\hline 5 & 75 & 100 & 1000 & 10 & 11.97 & 1.58 \\
\hline 6 & 75 & 100 & 1500 & 15 & 15.31 & 0.98 \\
\hline 7 & 75 & 300 & 2000 & 15 & 18.94 & 1.06 \\
\hline 8 & 100 & 300 & 1500 & 15 & 16.98 & 0.58 \\
\hline 9 & 75 & 500 & 2000 & 10 & 18.85 & 1.01 \\
\hline 10 & 75 & 500 & 1500 & 5 & 19.71 & 0.33 \\
\hline 11 & 100 & 300 & 2000 & 10 & 15.19 & 0.55 \\
\hline 12 & 75 & 300 & 1000 & 5 & 16.82 & 1.19 \\
\hline 13 & 75 & 100 & 1500 & 5 & 13.72 & 1.01 \\
\hline 14 & 100 & 300 & 1000 & 10 & 14.74 & 1.26 \\
\hline 15 & 75 & 100 & 2000 & 10 & 12.96 & 0.89 \\
\hline 16 & 75 & 300 & 1500 & 10 & 13.28 & 0.45 \\
\hline 17 & 50 & 300 & 1000 & 10 & 14.1 & 2.12 \\
\hline 18 & 75 & 500 & 1000 & 10 & 17.14 & 1.96 \\
\hline 19 & 75 & 300 & 1500 & 10 & 12.83 & 0.35 \\
\hline 20 & 75 & 300 & 2000 & 5 & 17.54 & 0.65 \\
\hline 21 & 75 & 300 & 1000 & 15 & 17.74 & 1.94 \\
\hline 22 & 50 & 100 & 1500 & 10 & 10.74 & 1.19 \\
\hline 23 & 75 & 300 & 1500 & 10 & 13.29 & 0.47 \\
\hline 24 & 50 & 300 & 1500 & 5 & 17.73 & 2.19 \\
\hline 25 & 100 & 300 & 1500 & 5 & 17.03 & 0.27 \\
\hline 26 & 50 & 300 & 1500 & 5 & 15.98 & 0.81 \\
\hline 27 & 50 & 300 & 2000 & 10 & 15.13 & 1.59 \\
\hline 28 & 100 & 500 & 1500 & 10 & 17.12 & 0.33 \\
\hline 29 & 50 & 500 & 1500 & 10 & 17.71 & 1.65 \\
\hline
\end{tabular}

TABLE 2: Experiment and measurement results.

content and residual stress are quantified by PCA. The calculation process is expressed as follows:

(a) Establishing the original sequence of various quality characteristics:

$$
x=\left[\begin{array}{cccc}
x_{1}(1) & x_{1}(2) & \cdots & x_{1}(n) \\
x_{2}(1) & x_{2}(2) & \cdots & x_{2}(n) \\
\vdots & \vdots & \vdots & \vdots \\
x_{m}(1) & x_{m}(2) & \cdots & x_{m}(n)
\end{array}\right],
$$

where $m$ is the number of experiments, $n$ is the number of response variables, and $x$ is the grey correlation coefficient of each response variable. 
(b) Calculation of the correlation coefficient array:

$$
R_{j l}=\left[\frac{\operatorname{Cov}\left(x_{i}(j), x_{i}(l)\right)}{\sigma x_{i}(j) \times \sigma x_{i}(l)}\right],
$$

where $\operatorname{Cov}\left(x_{i}(j), x_{i}(l)\right)$ is the covariance of $x_{i}(j)$ and $x_{i}(l)$ and $\sigma x_{i}(j)$ and $\sigma x_{i}(l)$ are the standard deviations of $x_{i}(j)$ and $x_{i}(l)$.

(c) Computation of eigenvalues and eigenvectors: $\lambda_{k}$ can be obtained by the following equation:

$$
\left|\lambda_{k} I_{m}-R\right|=0,
$$

where $I_{m}$ is the identity matrix and the eigenvalues $\lambda_{k}$ are arranged in the ascending order, i.e., $\lambda_{1} \geq \lambda_{2}$ $\geq \cdots \geq 0, k=1,2, \ldots, n$.

(d) Calculation of weight of the principal component:

$$
\begin{gathered}
a_{k}=\frac{\lambda_{k}}{\sum \lambda_{i i=1}^{n},} \\
N_{k}=\frac{\sum \lambda_{k i=1}^{k}}{\sum \lambda_{i i=1}^{n}} .
\end{gathered}
$$

Generally, $\lambda_{1}$ and $\lambda_{2}$ are called the first and second principal components if $N_{k}>85 \%$, respectively.

Step 4: calculation of the grey relational grade: GRG is the weighted sum of the grey relational coefficient and can be calculated by the following equation:

$$
\gamma\left(x_{0}^{*}, x_{i}^{*}\right)=\sum_{k=1}^{n} \beta_{k}\left(x_{0}^{*}(k), x_{i}^{*}(k)\right)
$$

where $\sum_{k=1}^{n} \beta_{k}=1$, and $\beta_{k}$ is the weight of the $k$ th response variable and determined by PCA.

3.2. Results for GRA. Principal component analysis for weight values and results for GRA are provide in Tables 3 and 4.

\section{The Grey Relational Grade Prediction Model}

According to PCA for weight values as shown in Table 3 and results for GRA as shown in Table 4, a mapping relation between the process parameters and the GRG can be established. Generally, a second-order mathematical regression model in response surface methodology is used to determine the relationship between the response variable and the input factor. The second-order GRG model for the winding process parameters can be expressed as follows:

$$
\widehat{y}=\mathrm{GRG}-\varepsilon=\rho_{0}+\sum_{i=1}^{4} \rho_{i} y_{i}+\sum_{i=1}^{4} \sum_{j=i+1}^{4} \rho_{i j} y_{i} y_{j}+\sum_{i=1}^{4} \rho_{i i} y_{i}^{2},
$$

where $\hat{y}$ is the estimated GRG value, $y_{i}$ is a winding process parameter, $\varepsilon$ is the experimental error, and each $\rho$ is a second-order regression coefficient. The second term models a linear effect, the third term models an interaction effect, and the fourth term models second-order effects.

GRG prediction model is based on regression analysis of experimental data using Minitab software. A comparison
TABLE 3: Principal component analysis for weight values.

\begin{tabular}{lcc}
\hline Principal component & Eigenvalue & Contribution (\%) \\
\hline Residual stress & 1.1013 & 55.1 \\
Void content & 0.8987 & 44.9 \\
Total & & 100 \\
\hline
\end{tabular}

between the predicted and calculated GRG values is shown in Figure 7. Figure 7 shows that the predicted GRG value is very close to the calculated value, with an average deviation of $1.22 \%$. Thus, there is no significant difference between the predicted value and the calculated value. The residual error in the prediction model is shown in Figure 8, which shows that residual errors are randomly distributed near zero without abnormal points. Thus, the prediction model is a good fit to the experimental data. Analysis of variance (ANOVA) results for the prediction model are shown in Table 5. One can see from the results in Table 5 that the coefficients of determination $(R-S q$ and $R-S q$ (adj)) are very close, indicating that the model is very reliable and accurate. The prediction model is shown in the following equation:

$$
\begin{aligned}
\hat{y}= & -1.395+0.00945 A-0.000461 B+0.001756 C \\
& +0.1097 D-0.000143 A^{2}-0.000001 B^{2}-0.000001 C^{2} \\
& -0.006405 D^{2}+0.000018 A B+0.000002 A C \\
& +0.000471 A D-0.000074 B D-0.000002 C D .
\end{aligned}
$$

\section{Multiresponse Parameter Optimization and Experimental Verification}

5.1. Analysis on Parameter Influence Laws. If the GRG is larger, the response variable will be better. Correspondingly, when the average GRG value for each process parameter is the largest, the response variable is the best. Table 6 shows that the optimal level of temperature is level $3\left(100^{\circ} \mathrm{C}\right)$, the optimal level of tension is level $1(100 \mathrm{~N})$, the optimal level of force is level $2(1500 \mathrm{~N})$, and the optimal level of rotation speed is level $2(10 \mathrm{rpm})$. The difference between minimum and maximum values shows that tension has the greatest impact on the multiobjective response followed by the influence of speed, force, and temperature. Figure 9 also shows that tension has the greatest impact on residual stress, while the impact of temperature is minimal. The aforementioned parameter combination yields products with minimum residual stress.

Figure 10 shows that temperature and force have a great impact on void content, while the impact of tension is minimal. The parameter combination yielding products with minimum void content is $50^{\circ} \mathrm{C}$ temperature, $100 \mathrm{~N}$ tension, $1000 \mathrm{~N}$ force, and $15 \mathrm{rpm}$ rotation speed. The influence of process parameters on GRG is given by the weighted sum of residual stress and void content. Therefore, the influence of process parameters on residual stress and void content can be determined by examining changes in the GRG value, and residual stress and void content can be optimized by optimizing GRG. 
TABLE 4: Results for GRA.

\begin{tabular}{|c|c|c|c|c|c|c|c|}
\hline \multirow{2}{*}{ No. } & \multicolumn{2}{|c|}{ Comparison sequence } & \multicolumn{2}{|c|}{ Deviation sequence } & \multicolumn{2}{|c|}{ GRC } & \multirow{2}{*}{ GRG } \\
\hline & $x_{i}^{*}(\mathrm{RS})$ & $x_{i}^{*}(\mathrm{VC})$ & $\Delta_{0 i}(\mathrm{RS})$ & $\Delta_{0 i}(\mathrm{VC})$ & GRC (RS) & GRC (VC) & \\
\hline$\overline{1}$ & 0.851772 & 0.655914 & 0.148228 & 0.344086 & 0.771334 & 0.592357 & 0.690973 \\
\hline 2 & 0 & 0.338709 & 1 & 0.661290 & 0.333333 & 0.430555 & 0.376986 \\
\hline 3 & 0.729323 & 1 & 0.270676 & 0 & 0.648780 & 1 & 0.806478 \\
\hline 4 & 0.700322 & 0.940860 & 0.299677 & 0.059139 & 0.625251 & 0.894230 & 0.746023 \\
\hline 5 & 0.867883 & 0.327956 & 0.132116 & 0.672043 & 0.790994 & 0.426605 & 0.627383 \\
\hline 6 & 0.509129 & 0.650537 & 0.490870 & 0.349462 & 0.504607 & 0.588607 & 0.662323 \\
\hline 7 & 0.119226 & 0.607526 & 0.880773 & 0.392473 & 0.362115 & 0.560240 & 0.451074 \\
\hline 8 & 0.329752 & 0.865591 & 0.670247 & 0.134408 & 0.427260 & 0.788135 & 0.589293 \\
\hline 9 & 0.128893 & 0.634408 & 0.871106 & 0.365591 & 0.36466 & 0.577639 & 0.500292 \\
\hline 10 & 0.036519 & 1 & 0.963480 & 0 & 0.341651 & 1 & 0.607724 \\
\hline 11 & 0.522019 & 0.881720 & 0.477980 & 0.118279 & 0.511257 & 0.808695 & 0.644807 \\
\hline 12 & 0.346938 & 0.537634 & 0.653061 & 0.462365 & 0.433628 & 0.519553 & 0.472208 \\
\hline 13 & 0.679914 & 0.634408 & 0.320085 & 0.365591 & 0.609692 & 0.577639 & 0.595300 \\
\hline 14 & 0.570354 & 0.5 & 0.429645 & 0.5 & 0.537839 & 0.5 & 0.520849 \\
\hline 15 & 0.761546 & 0.698924 & 0.238453 & 0.301075 & 0.677090 & 0.624161 & 0.653325 \\
\hline 16 & 0.727175 & 0.935483 & 0.272824 & 0.064516 & 0.646977 & 0.885714 & 0.754170 \\
\hline 17 & 0.639097 & 0.037634 & 0.360902 & 0.962365 & 0.580786 & 0.341911 & 0.473531 \\
\hline 18 & 0.312567 & 0.268817 & 0.687432 & 0.731182 & 0.421076 & 0.406113 & 0.414358 \\
\hline 19 & 0.775510 & 0.989247 & 0.224489 & 0.010752 & 0.334769 & 0.978947 & 0.819814 \\
\hline 20 & 0.269602 & 0.827956 & 0.730397 & 0.172043 & 0.406372 & 0.744 & 0.557967 \\
\hline 21 & 0.248120 & 0.134408 & 0.751879 & 0.865591 & 0.399399 & 0.366141 & 0.384466 \\
\hline 22 & 1 & 0.537634 & 0 & 0.462365 & 1 & 0.519553 & 0.784279 \\
\hline 23 & 0.726100 & 0.924731 & 0.273899 & 0.075268 & 0.646079 & 0.869158 & 0.746241 \\
\hline 24 & 0.249194 & 0 & 0.750805 & 1 & 0.399742 & 0.333333 & 0.369924 \\
\hline 25 & 0.324382 & 0.763440 & 0.675617 & 0.236559 & 0.425308 & 0.678832 & 0.539140 \\
\hline 26 & 0.437164 & 0.741935 & 0.562835 & 0.258064 & 0.470439 & 0.659574 & 0.555361 \\
\hline 27 & 0.528464 & 0.322580 & 0.471535 & 0.677419 & 0.514648 & 0.424657 & 0.474242 \\
\hline 28 & 0.314715 & 1 & 0.685284 & 0 & 0.421839 & 1 & 0.681433 \\
\hline 29 & 0.251342 & 0.290322 & 0.748657 & 0.709677 & 0.400430 & 0.413333 & 0.406223 \\
\hline
\end{tabular}

Notes: $\Delta_{0 i}$ : deviation sequence; $x_{i}^{*}$ : comparison sequence; GRC: grey relational coefficient; RS: residual stress; and VC: void content.

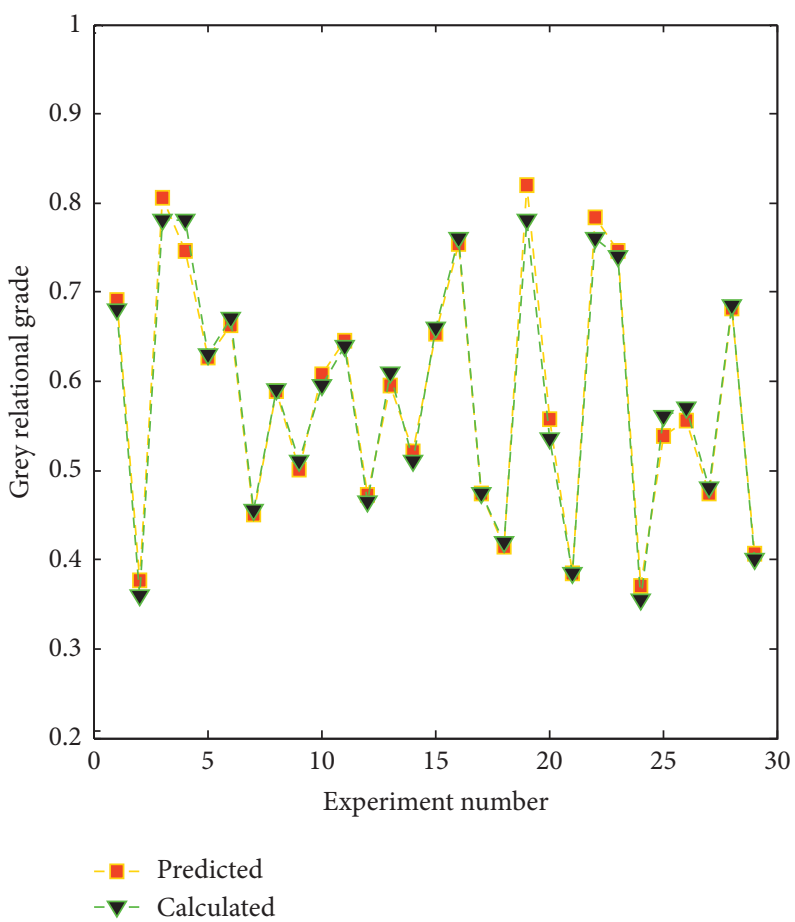

FIGURE 7: Comparison chart of the experimental value and the predicted value of GRG. 


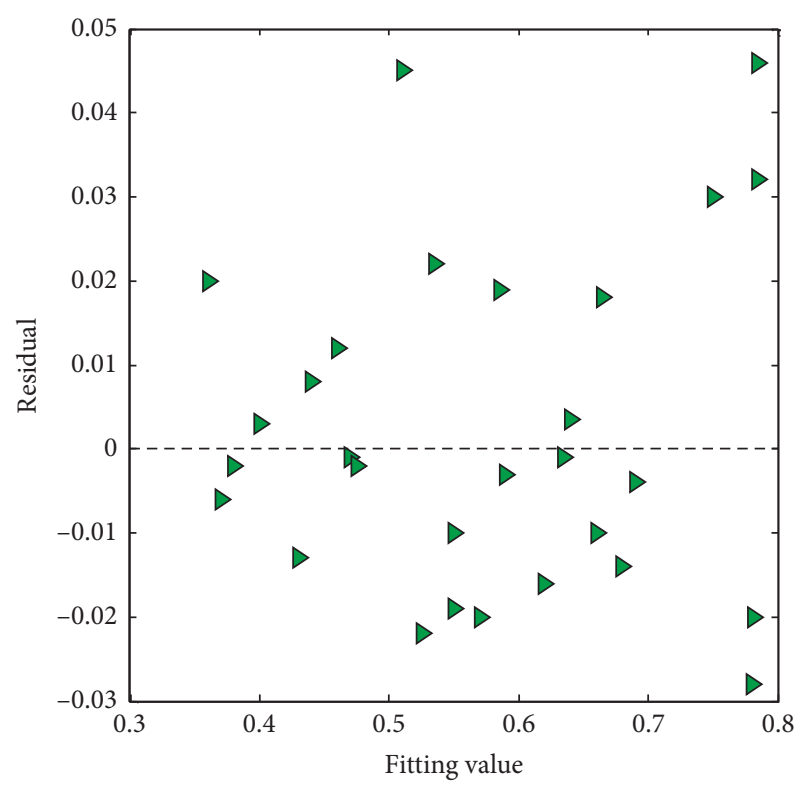

FIgURE 8: Residual plot for the GRG prediction model.

TABLE 5: ANOVA for the response surface model.

\begin{tabular}{lccccc}
\hline Source & DF & SS & MS & $F$ & $F_{0.01}$ \\
\hline Regression model & 14 & 0.512881 & 0.036634 & 52.26 & 3.698 \\
Error & 14 & 0.009813 & 0.000701 & & \\
Total & 28 & 0.522695 & & & \\
Standard deviation & $R-S q=98.12 \% R-S q$ (adj) $=$ \\
& $96.25 \%$ & & \\
\hline
\end{tabular}

Notes: DF: degree of freedom; SS: sum of square; MS: mean square; and SD: standard deviation.

TABLE 6: The average grey relational grade of each parameter.

\begin{tabular}{lcccc}
\hline Process parameters & Temperature & Tension & Force & Speed \\
\hline Level 1 & 0.5105 & 0.6689 & 0.4821 & 0.5446 \\
Level 2 & 0.5985 & 0.5826 & 0.6312 & 0.6320 \\
Level 3 & 0.6110 & 0.4978 & 0.5469 & 0.4723 \\
Max-min & 0.0905 & 0.1701 & 0.1491 & 0.1597 \\
\hline
\end{tabular}

5.2. Optimal Parameters. The GRG prediction model is analyzed using the response optimizer in Minitab software. Figure 11 shows that the optimal GRG is 0.8106 as calculated with the weighting method, and the optimal parameter combination is $70.20^{\circ} \mathrm{C}$ temperature, $100.08 \mathrm{~N}$ tension, $1515.15 \mathrm{~N}$ force, and $10.25 \mathrm{rpm}$ rotation speed. Figure 12 shows that the optimal GRG value is 0.8077 when calculated with the equal weight method, and the optimal parameter combination is $78.789^{\circ} \mathrm{C}$ temperature, $237.37 \mathrm{~N}$ tension, $1555.55 \mathrm{~N}$ force, and $9.545 \mathrm{rpm}$ rotation speed.

5.3. Experimental Verification. Once the optimum combination of process parameters is determined, a confirmation experiment is conducted to validate the optimal solution. The results of the eighth experiment are used as the comparative group. Table 7 shows the comparison of winding experimental results between the initial parameter values and the optimum process parameters. The results show that

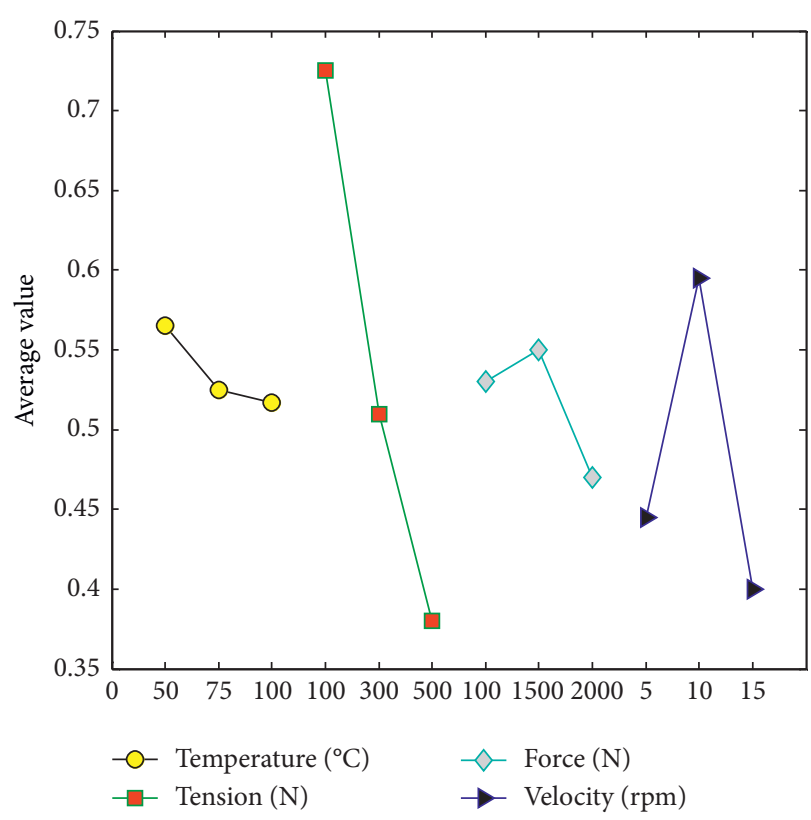

FIgURE 9: Main effect plot of GCC (residual stress).

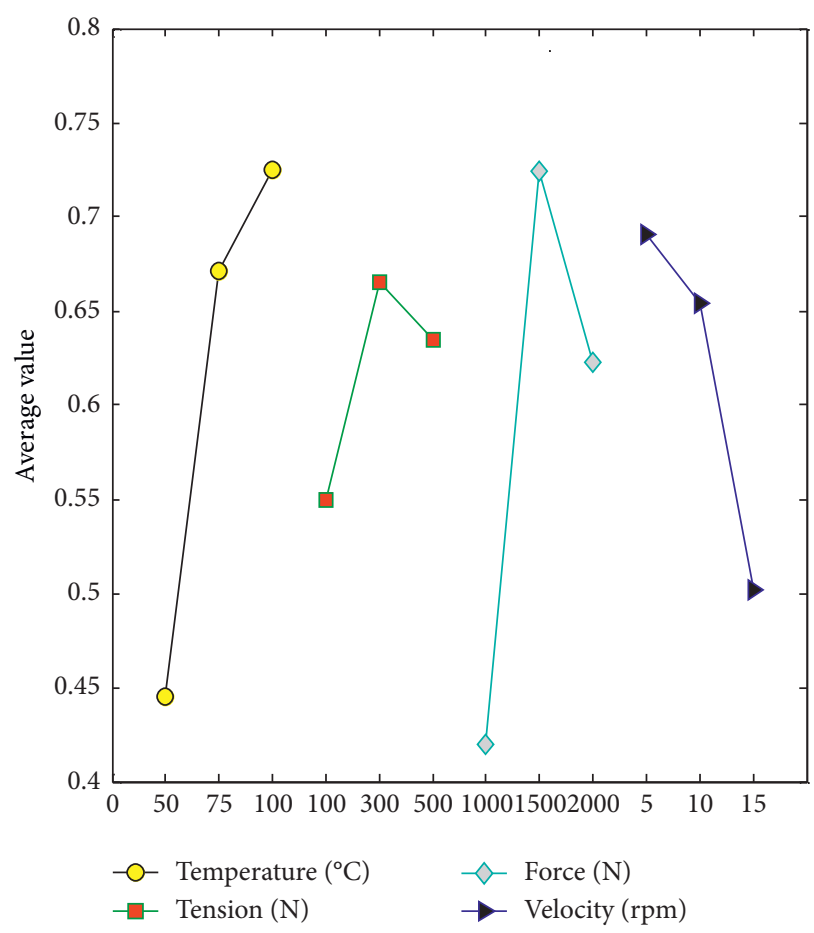

FIGURE 10: Main effect plot of GCC (void content).

the proposed method can effectively reduce the residual stress and the void content of the composite winding product.

The winding experiment is carried out with parameter combination calculated by the weighting method and parameter combination calculated by the equal weight method. Table 8 shows that the equal weight optimization parameter combination produces lower residual stress, but the void content in the product is greater than $0.95 \%$. In order to ensure the mechanical properties of composite products, the 


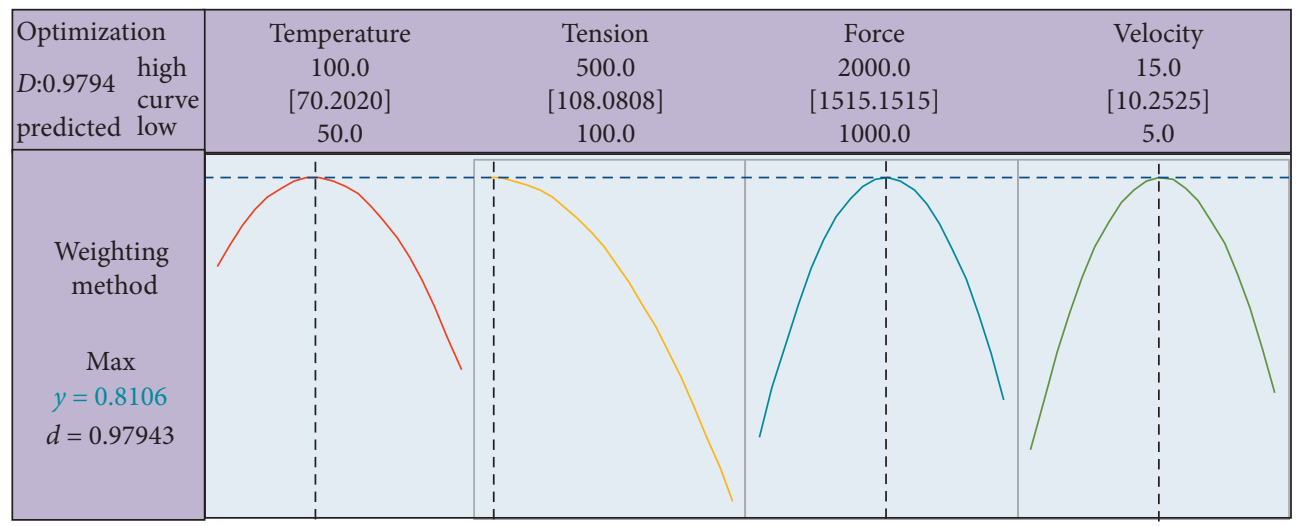

FIGURE 11: Optimal process parameter combination (weighting method).

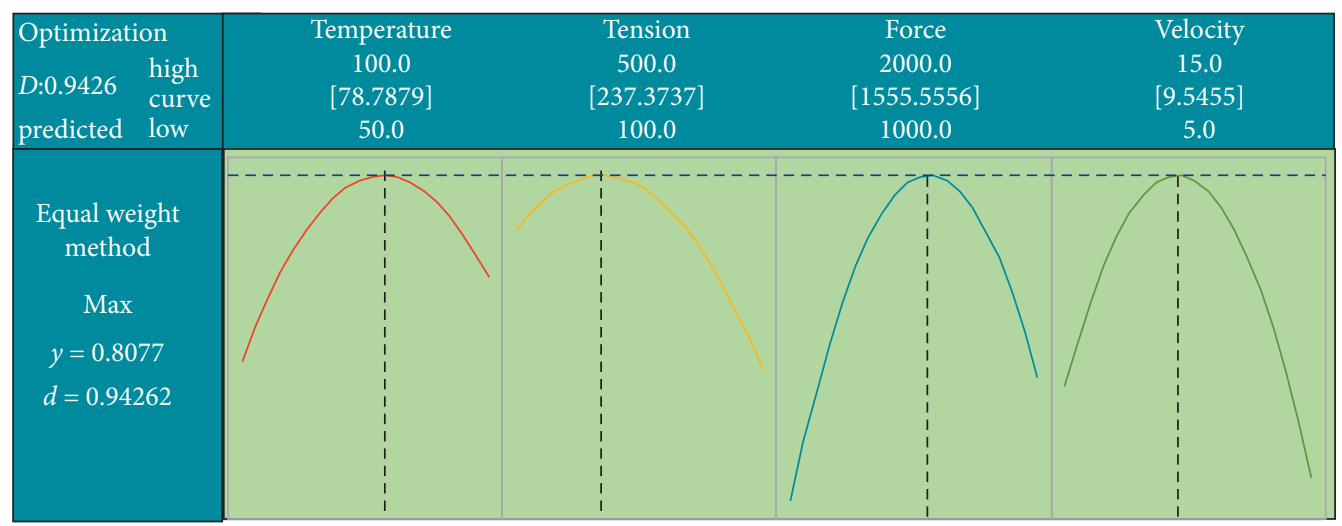

FIGURE 12: Optimal process parameters (equal weight method).

TABLE 7: Comparison between the initial and optimum process parameters.

\begin{tabular}{|c|c|c|c|c|}
\hline & \multirow{2}{*}{ Initial process parameter value } & \multicolumn{2}{|c|}{ Optimal process condition } & \multirow{2}{*}{ Improvement (\%) } \\
\hline & & Prediction & Experimental value & \\
\hline Temperature $\left({ }^{\circ} \mathrm{C}\right)$ & 75 & 70.02 & 70.02 & \\
\hline Tension $(\mathrm{N})$ & 300 & 100.08 & 100.08 & \\
\hline Force $(\mathrm{N})$ & 1500 & 1515.15 & 1515.15 & \\
\hline Velocity (rpm) & 10 & 10.25 & 10.25 & \\
\hline Residual stress (MPa) & 13.29 & & 11.12 & 16.3 \\
\hline Void content $(\%)$ & 0.47 & & 0.38 & 19.1 \\
\hline GRG & 0.7462 & 0.8106 & 0.8123 & 8.8 \\
\hline
\end{tabular}

TABLE 8: Experimental results of different process parameters' combination.

\begin{tabular}{lcccccc}
\hline Experimental scheme & $A$ & $B$ & $C$ & $D$ & Residual stress (MPa) & Void content (\%) \\
\hline Equal weight method & 78.78 & 237.3 & 1555 & 9.545 & 9.68 & 0.96 \\
Weighting method & 70.02 & 100.08 & 1515 & 10.25 & 11.12 & 0.38 \\
\hline
\end{tabular}

void content should be kept at a low value, especially for special aeronautical parts. The experimental results show that the weighted method is better than the equal weight method in the winding process.

\section{Conclusion}

(1) The optimization of composite tape winding process parameters is a multiparameter input and multiobjective response. A procedure integrating the Box-Behnken design, RSM, and GRA is used to predict the optimal process conditions for reducing the residual stress and void content in composite products.

(2) The GRG prediction model was established using Box-Behnken design based on experimental data. ANOVA results show that the prediction model is reliable and significant. The optimal combination of 
process parameters was found to be $70.02^{\circ} \mathrm{C}$ temperature, $100.08 \mathrm{~N}$ tension, $1515.15 \mathrm{~N}$ force, and $10.25 \mathrm{rpm}$ winding speed. The predicted results are in good agreement with the experimental results. Residual stress and void content can be improved by using optimized parameter combination to carry out the winding process.

(3) Comparing the experimental results of weighted optimal parameter combination and equal weight optimal parameter combination, the experimental results show that GRA based on equal weight has some limitations in optimizing the parameters of the composite tape winding process, and the weighted GRA method proposed in this paper has obvious advantages.

\section{Data Availability}

The data used to support the findings of this study are available from the corresponding author upon request.

\section{Conflicts of Interest}

The authors declare that they have no conflicts of interest.

\section{Acknowledgments}

This article was supported by the National Natural Science Foundation of China (grant nos. 51475377 and 51375394).

\section{References}

[1] P. Nimdum, B. Patamaprohm, J. Renard, and S. Villalonga, "Experimental method and numerical simulation demonstrate non-linear axial behaviour in composite filament wound pressure vessel due to thermal expansion effect," International Journal of Hydrogen Energy, vol. 40, no. 38, pp. 13231-13241, 2015.

[2] R. Rafiee, "Experimental and theoretical investigations on the failure of filament wound GRP pipes," Composites Part B-Engineering, vol. 45, no. 1, pp. 257-267, 2013.

[3] M. Tannous, A. Barasinski, C. Binetruy, and B. Courtemanche, "Contribution of thermo-mechanical parameters and friction to the bonding of thermoplastic tapes in the tape winding process," Journal of Materials Processing Technology, vol. 229, no. 8, pp. 587-595, 2016.

[4] J. Grunewald, P. Parlevliet, and V. Altstadt, "Definition of process parameters for manufacturing of thermoplastic composite sandwiches-part A: modelling," Journal of Thermoplastic Composite Materials, vol. 31, no. 6, pp. 745-766, 2016.

[5] F. O. Sonmez and H. T. Hahn, "Analysis of the on-line consolidation process in thermoplastic composite tape placement," Journal of Thermoplastic Composite Materials, vol. 10, no. 6, pp. 545-566, 1997.

[6] H. Lu, M. Schlottermuller, N. Himmel, and R. Schledjewski, "Effects of tape tension on residual stress in thermoplastic composite filament winding," Journal of Thermoplastic Composite Materials, vol. 18, no. 6, pp. 469-487, 2005.

[7] M. Schlottermuller, H. Lu, Y. Roth, N. Himmel, R. Schledjewski, and P. Mitschang, "Thermal residual stress simulation in thermoplastic filament winding process,"
Journal of Thermoplastic Composite Materials, vol. 16, no. 6, pp. 497-519, 2003.

[8] E. Guzman-Maldonado, N. Hamila, N. Naouar, G. Moulin, and P. Boisse, "Simulation of thermoplastic prepreg thermoforming based on a visco-hyperelastic model and a thermal homogenization," Materials \& Design, vol. 93, no. 49, pp. 431-442, 2016.

[9] P. Xu, J. Y. Zheng, H. G. Chen, and P. F. Liu, "Optimal design of high pressure hydrogen storage vessel using an adaptive genetic algorithm," International Journal of Hydrogen Energy, vol. 35, no. 7, pp. 2840-2846, 2010.

[10] P. F. Liu and J. Y. Zheng, "Strength reliability analysis of aluminium-carbon fiber/epoxy composite laminates," Journal of Loss Prevention in the Process Industries, vol. 23, no. 3, pp. 421-427, 2010.

[11] Y. Shi, T. Yu, X. He, C. Kang, X. Zhang, and J. Zhang, "Mechanism and optimization of process parameters coupling for composite tape winding," Acta Materiae Compositae Sinica, vol. 32, no. 3, pp. 831-839, 2015.

[12] R. L. Pagano, V. M. A. Calado, M. B. D. Souza, and E. C. Biscaia, "Proposal of an optimum cure cycle for filament winding process using a hybrid neural network-first principles model," Polymer Composites, vol. 35, no. 7, pp. 13771387, 2014.

[13] P. Wang, Z. Q. Zhu, and Y. H. Wang, "A novel hybrid MCDM model combining the SAW, TOPSIS and GRA methods based on experimental design," Information Sciences, vol. 345, pp. 27-45, 2016.

[14] R. Verma and N. P. Singh, "GRA based network selection in heterogeneous wireless networks," Wireless Personal Communication, vol. 72, no. 2, pp. 1437-1452, 2013.

[15] G. Anbuchezhiyan, T. Muthuramalingam, and B. Mohan, "Effect of process parameters on mechanical properties of hollow glass microsphere reinforced magnesium alloy syntactic foams under vacuum die casting," Archives of Civil and Mechanical Engineering, vol. 18, no. 4, pp. 1645-1650, 2018.

[16] P. Nanthakumar, A. Rajadurai, and T. Muthuramalingam, "Multi response optimization on mechanical properties of silica fly ash filled polyester composites using taguchi-grey relational analysis," Silicon, vol. 10, no. 4, pp. 1723-1729, 2018.

[17] K. S. Prasad, S. R. Chalamalasetti, and N. R. Damera, "Application of grey relational analysis for optimizing weld bead geometry parameters of pulsed current micro plasma arc welded inconel 625 sheets," The International Journal of Advanced Manufacturing Technology, vol. 78, no. 1-4, pp. 625-632, 2015.

[18] J. Kundu and H. Singh, "Friction stir welding of AA5083 aluminium alloy: multi-response optimization using Taguchibased grey relational analysis," Advances in Mechanical Engineering, vol. 8, no. 11, pp. 1-10, 2016.

[19] S. T. Kumaran, M. Uthayakumar, A. Slota, and J. Zajac, "Application of grey relational analysis in high speed machining of AA (6351)-SiC- $\mathrm{B}_{4 \mathrm{C}}$ hybrid composite," International Journal of Materials \& Product Technology, vol. 51, no. 1, pp. 17-31, 2015.

[20] S. Y. Du, M. Chen, L. S. Xie, Z. S. Zhu, and X. N. Wang, "Optimization of process parameters in the high-speed milling of titanium alloy TB17 for surface integrity by the taguchi-grey relational analysis method," Advances in $\mathrm{Me}$ chanical Engineering, vol. 8, no. 10, pp. 1-12, 2016.

[21] J. H. Zhou, J. X. Ren, and W. J. Tian, "Grey-RBF-FA method to optimize surface integrity for inclined end milling Inconel 718," The International Journal of Advanced Manufacturing Technology, vol. 91, no. 9-12, pp. 2975-2993, 2017. 
[22] J. H. Zhou, J. X. Ren, and C. F. Yao, "Multi-objective optimization of multi-axis ball-end milling Inconel 718 via grey relational analysis coupled with RBF neural network and PSO algorithm," Measurement, vol. 102, pp. 271-285, 2017.

[23] S.-C. Huang and T.-P. Dao, "Multi-objective optimal design of a 2-DOF flexure-based mechanism using hybrid approach of grey-Taguchi coupled response surface methodology and entropy measurement," Arabian Journal for Science and Engineering, vol. 41, no. 12, pp. 5215-5231, 2016.

[24] S.-C. Huang and T.-P. Dao, "Design and computational optimization of a flexure-based XY positioning platform using FEA-based response surface methodology," International Journal of Precision Engineering and Manufacturing, vol. 17, no. 8, pp. 1035-1048, 2016.

[25] R. B. Azhiri, R. Teimouri, M. G. Baboly, and Z. C. Leseman, "Application of Taguchi, ANFIS and grey relational analysis for studying, modeling and optimization of wire EDM process while using gaseous media," The International Journal of Advanced Manufacturing Technology, vol. 71, no. 1-4, pp. 279-295, 2014.

[26] A. Varun and N. Venkaiah, "Simultaneous optimization of WEDM responses using grey relational analysis coupled with genetic algorithm while machining EN 353," The International Journal of Advanced Manufacturing Technology, vol. 76, no. 1-4, pp. 675-690, 2015.

[27] M. Thangaraj, R. Annamalai, K. Moiduddin, M. Alkindi, S. Ramalingam, and O. Alghamdi, "Enhancing the surface quality of micro titanium alloy specimen in WEDM process by adopting TGRA-based optimization," Materials, vol. 13, no. 6, p. $1440,2020$.

[28] T. Muthuramalingam, "Effect of diluted dielectric medium on spark energy in green EDM process using TGRA approach," Journal of Cleaner Production, vol. 238, Article ID 117894, 2019.

[29] T. Geethapriyan, K. Kalaichelvan, T. Muthuramalingam, and A. Rajadurai, "Performance analysis of process parameters on machining $\alpha-\beta$ titanium alloy in electrochemical micromachining process," Proceedings of the Institution of $\mathrm{Me}$ chanical Engineers, Part B: Journal of Engineering Manufacture, vol. 232, no. 9, pp. 1577-1589, 2018.

[30] A. Ramamurthy, R. Sivaramakrishnan, and T. Muthuramalingam, "Taguchi-grey computation methodology for optimum multiple performance measures on machining titanium alloy in WEDM process," Indian Journal of Engineering and Materials Sciences, vol. 22, no. 2, pp. 181-186, 2015.

[31] J. W. Kim and D. G. Lee, "Measurement of Residual Stresses in thick composite cylinders by the radial-cut-cylinder-bending method," Composite Structures, vol. 77, no. 4, pp. 444-456, 2007.

[32] J. W. Kim, J. H. Lee, H. G. Kim, H. S. Kim, and D. G. Lee, "Reduction of residual stresses in thick-walled composite cylinders by smart cure cycle with cooling and reheating," Composite Structures, vol. 75, no. 1-4, pp. 261-266, 2006.

[33] S. Paciornik and J. D'Almeida, "Digital microscopy and image analysis applied to composite materials Characterization," Materia-Rio De Janeiro, vol. 15, no. 2, pp. 172-181, 2010.

[34] B. N. Fedulov, F. K. Antonov, A. A. Safonov, A. E. Ushakov, and S. V. Lomov, "Influence of fibre misalignment and voids on composite laminate strength," Journal of Composite Materials, vol. 49, no. 23, pp. 2887-2896, 2015.

[35] K. Croft, L. Lessard, D. Pasini, M. Hojjati, J. Chen, and A. Yousefpour, "Experimental study of the effect of automated fiber placement induced defects on performance of composite laminates," Composites Part A-Applied Science and Manufacturing, vol. 42, no. 5, pp. 484-491, 2011.

[36] T. Okuya, M. Nakada, and Y. Miyano, "Reliable test method for tensile strength in longitudinal direction of unidirectional carbon fiber-reinforced plastics," Journal of Reinforced Plastics and Composites, vol. 32, no. 21, pp. 1579-1585, 2013.

[37] B. Deng and Y. Y. Shi, "Modeling and simulation of voids in composite tape winding process based on domain superposition technique," Applied Composite Materials, vol. 25, no. 2, pp. 1219-1236, 2018.

[38] Standardization Administration of the People's Republic of China, Test Method for Mechanical Properties of Ring of Filament-Winding Reinforced Plastics, Standardization Administration of the People's Republic of China, Beijing, China, 2008.

[39] S. Paciornik and J. R. M. D'Almeida, "Measurement of void content and distribution in composite materials through digital microscopy," Journal of Composite Materials, vol. 43, no. 2, pp. 101-112, 2009.

[40] H. Y. Zhu, B. C. Wu, D. H. Li, D. G. Zhang, and Y. Y. Chen, "Influence of voids on the tensile performance of carbon/ epoxy fabric laminates," Journal of Materials Science \& Technology, vol. 27, no. 1, pp. 69-73, 2011.

[41] Y. Nikishkov, L. Airoldi, and A. Makeev, "Measurement of voids in composites by X-ray computed tomography," Composites Science and Technology, vol. 89, pp. 89-97, 2013.

[42] Carbon fiber reinforced plastics determination void content and fiber volume national standards of the people's republic of China. 